\title{
Playing Technologies as Mean for Development of Linguistic Competence of Foreign Students during Studying of Language History
}

\author{
Sarapas Marina Vladimirovna ${ }^{1}$ \\ Associate Professor, Moscow State Pedagogical University, \\ Moscow, Russia. \\ (date of receiving: July, 2019; date of acceptance: December, 2019)
}

\begin{abstract}
There is increasing of the interest to playing technologies extensively using in educational space at the modern stage of teaching of Russian as a foreign language. Playing activity causes students' linguistic competence building and allows beefing up their background knowledge. The one of the most efficient mean for arouse an interest to Russian language history is didactic game. Using of various playing technologies in auditory of other languages causes the increasing of interest to Russian language and its history. Linguistic facts become more accessible and understandable. The main attention during material take-off for historical commentary should be paid to its practical focus that provides the formation of communicative, linguistic and culturological competence of foreign students. The article presents didactic principles of material take-off for playing technologies, adduces examples of linguistic games oriented to training of difficult for foreign students themes related to Russian language history such as orthography, phonetic, grammar.
\end{abstract}

Keywords: Russian as a Foreign Language, Teaching Methodology of Russian as a Foreign Language, Russian Language History, Playing Technologies, Didactic Game.

1. E-mail: sarapas@yandex.ru 


\section{Игровые технологии как средство развития лингвистических компетенций иностранных студентов при изучении истории языка}

\section{Сарапас Марина Владимировна ${ }^{1}$}

Доцент, Московский педагогический государственный университет, Москва, Россия.

(дата получения: июль 2019 г.; дата принятия: декабрь 2019 г.)

\section{Аннотация}

На современном этапе преподавания русского языка как иностранного наблюдается рост интереса к игровым технологиям, активно используемым в образовательном пространстве. Игровая деятельность способствует повышению лингвистической компетенции обучаемых, а также позволяет расширить их фоновые знания.

Дидактическая игра является одним из наиболее действенных средств, способных вызвать интерес к истории русского языка. При использовании в иноязычной аудитории различных игровых технологий интерес к русскому языку, к его истории возрастает, языковые факты становятся для иностранных студентов более доступными и понятными.

При отборе материала главное внимание должно быть уделено его практической направленности, что обеспечивает формирование у иностранных студентов коммуникативной, языковой и культуроведческой компетенции.

В статье представлены дидактические принципы отбора языкового материала для игровых технологий, приводятся примеры лингвистических игр, направленные на отработку трудных для иностранных студентов орфографических, фонетических и грамматических тем, связанных с историей русского языка.

Ключевые слова: Русский Язык Как Иностранный, Методика Обучения Русскому Языку Как Иностранному, История Русского Языка, Игровые Технологии, Дидактическая Игра.

1. E-mail: sarapas@yandex.ru 


\section{Введение}

На современном этапе преподавания русского языка как иностранного наблюдается рост интереса к игровым технологиям, активно используемым в образовательном пространстве. Игровая деятельность способствует повышению лингвистической компетенции обучаемых, связанной с углублением их знаний о языке, его устройстве, развитии и функционировании, с овладением основными нормами русского литературного языка, обогащением словарного запаса и грамматического строя речи, совершенствованием способности к анализу и оценке языковых явлений и фактов, а также позволяет расширить их фоновые знания.

Термин «дидактическая игра» был введён Ф. Фребелем и М. Монтессори в начале XX века. В методике преподавания русского языка как иностранного игра стала использоваться как элемент обучения в 70-х годах XX в., что было связано с внедрением коммуникативной методики в практику обучения иностранным языкам.

Популяризации игровых методик способствовало и развитие метода интенсивного обучения, в частности методика Г.А. Китайгородской, построенная, кроме суггестивных принципов, на активном использовании принципов игровой организации обучения.

\section{Основная часть}

Рост интереса к игровым технологиям, активно используемым в современном образовательном пространстве, объясняется их мотивирующим потенциалом. К тому же игры часто становятся «средством формирования культуры выходов из кризисов с помощью рефлексии» (Крючкова 2009. 70). Современные учебные пособия уже трудно представить без игровых заданий.

Дидактическая игра является одним из наиболее действенных средств, способных вызвать интерес к истории русского языка. При использовании в 
иноязычной аудитории различных игровых технологий интерес к русскому языку, к его истории возрастает, языковые факты становятся для иностранных студентов более доступными и понятными. Многие факты современного русского языка трудно объяснить, не обращаясь к истории языка. Исторические справки могут явиться ценным средством создания на уроках и во внеурочной деятельности разного рода проблемных ситуаций.

При отборе материала главное внимание должно быть уделено его практической направленности, что обеспечивает формирование у иностранных студентов коммуникативной, языковой и культуроведческой компетенции.

Рассмотрим примеры заданий лингвистических игр при изучении раздела «Фонетика и графика». Прежде всего, иностранным учащимся необходимо дать исторические сведения об одной из первых славянских азбук кириллице, созданной славянскими первоучителями, свв. братьями Кириллом и Мефодием.

Русская азбука прошла долгий путь развития, в результате которого в ней закрепилось 33 буквы. Однако первоначально в кириллице, созданной славянскими первоучителями, свв. братьями Кириллом и Мефодием, буквенных символов было гораздо больше - 43. Взятый за основу греческий алфавит был дополнен буквами, призванными передавать специфические звуки славянской речи. При этом некоторые из букв славянской азбуки оказались дублетными, например, перенесённые из греческого алфавита «о» и «W» служили обозначением разных звуков греческого языка, [о] краткого и [о] долгого, но в славянских языках эти звуки не различались; также в кириллице было 3 буквы для обозначения звука «и»: и - ижеи, или и- десятиричное, i иже, или и-восьмиричное и ижица; две буквы для обозначения звука «з»: зело и земля и две буквы для обозначения звука «ф»: фита и ферт; буквы $\mathbf{3}$ (кси) и ע (пси) были дублетами буквосочетаний «кс» и «пс», поскольку предназначались для передачи частотных в греческом, но редких в славянском 
языке сочетаний $[\kappa c]$ и [пс]. Возникает вопрос: зачем такая избыточность? Дело в том, что славяне вслед за греками использовали буквы не только для обозначения звуков речи, но и для обозначения чисел. За каждой буквой греческого алфавита было закреплено особое числовое значение. Были буквы для обозначения единиц, десятков и сотен, поэтому и такое большое количество букв в кириллице, и по нескольку букв для обозначения одного и того же звука.

Современному количественному и качественному состоянию русской азбуки способствовал целый ряд реформ. Две фундаментальных реформы - это реформа графики Петра I (1707 - 1710 гг.) и орфографическая реформа 1917 1918 гг., а между ними три менее значимые реформы, проведённые Академией наук в 1735, 1738, 1758 гг.

Исторические изменения алфавитно-буквенного состава русской азбуки условно можно разделить на три группы:

1) исключение букв, заимствованных из греческого алфавита и с самого начала ненужных для передачи звуков славянской речи, а также букв, ставших ненужными вследствие исторических изменений в фонетике русского языка;

2) изменение в значении и применении некоторых букв в соответствии с историческими изменениями в звуковом строе русского языка;

3) введение в русскую азбуку недостающих новых букв.

Рассмотрим все эти изменения в хронологической последовательности по группам.

K началу XVIII в. в русской азбуке было 9 ненужных букв, заимствованных из греческого алфавита. Суть петровской реформы заключалась в упрощении состава русской азбуки за счёт исключения из неё таких избыточных букв, как «пси», «кси», «омега», «ижица», «ять», «юс малый» (остальные три юса - юс 
малый йотированный, юс большой и юс большой йотированный - перестали применяться в русском письме ещё раньше), упразднении омофоничных пар «ижеи - иже» (И-I), «зело - земля» (S-3), «фита - ферт» (-ө- ф). Однако впоследствии часть этих букв была восстановлена в употреблении.

В 1708 году был создан новый русский, так называемый «гражданский», шрифт, причём в изготовлении эскизов букв принимал активное участие сам Пётр I, который исключил из русской азбуки 8 из девяти вышеперечисленных букв: пси, кси, омегу, ижицу, юс малый, а также ферт (оставив фиту), землю (оставив зело), иже (i), оставив ижеи (и). Однако впоследствии большинство из этих букв Пётр 1 восстановил и в учебную азбуку 1710 года не вошли только юсы, пси и омега. В 1710 году был утверждён образец нового шрифта азбуки. В ходе введения гражданского шрифта появилась буква Э («Э» оборотное), для того чтобы отличать её от йотованной буквы Е, а юс малый был вытеснен буквой Я (восходящей к одному из его скорописных вариантов). В результате этого с 1711 по 1735 годы русские гражданские книги набирались различно то одним, то другим составом азбуки.

В гражданском шрифте впервые устанавливаются прописные (большие) и строчные (малые) буквы. Всем буквам были приданы более округлые и простые начертания, приближавшие гражданский печатный шрифт к широко распространенному в те годы в Европе латинскому шрифту «антиква». Отменены были надстрочные знаки: придыхания, «силы» (значки ударений), титла (сокращения), которые активно использовались в древнерусских текстах для экономии писчего материала. Под титлами писали слова, часто употребляемые в текстах и понятные всем пишущим и читающим, такие как: бог, богородица, господь, ангел, отец, сын и другие. Также титла употреблялись для написания чисел: над буквой ставилась скобочка - значок титла и точки по бокам. В результате петровской реформы были отменены числовые значения славянских букв и окончательно введена арабская 
цифровая система. Главное же значение графической реформы состояло в том, что она предоставляла большие возможности для развития русского литературного языка.

Реформа Петра 1 повлекла за собой ряд других реформ, осуществлённых Академией наук. В 1735 году Академией наук были дополнительно исключены буквы кси, ижица, зело. В 1738 году і - десятиричное стало писаться с одной точкой вместо двух и упорядочено употребление этой буквы: перед гласными звуками, перед и - восьмиричное и в слове «мір» (в значении «вселенная»). А в 1758 году Академия наук снова восстанавливает ненужную ижицу.

К началу 20 века в русской азбуке всё ещё оставалось 4 ненужных буквы для передачи русской речи: и - десятиричное (i), фита, ижица, ять. Все эти буквы были окончательно упразднены орфографической реформой 1917 1918 годов. Наибольшие споры вызывал вопрос, какую из двух «и» оставить («і» или «и»). Аргументы в пользу «і»: 1) желательность приближения русского алфавита к западноевропейским (в латинице именно такой вид имеет буква «и»); 2) экономия бумаги при письме и печати; 3) «і» отличалась гораздо лучшей различимостью ( «и» слишком похожа по своей форме на две другие русские буквы - «н» и «п». Но победу одержали сторонники «и восьмиричного», аргументируя это тем, что данная буква чаще употреблялась и её сохранение приведёт к меньшему изменению традиционной графики русского письма.

Вопрос о реформировании русского письма занимал в разное время умы многих ученых и литераторов. Так, М.В. Ломоносов написал в 50-е годы XVIII века юмористический «Суд российских письмен...», в котором Грамматика выносит на суд Разума и Обычая «великие распри о получении разных важных мест и достоинств» между русскими буквами.

Бурный всплеск интереса к различным филологическим и педагогическим проблемам, связанным с русской азбукой, возникает в 20-30-е годы XIX 
столетия, после выхода в свет "Пространной русской грамматики" Н.И. Греча. В периодической печати появляются многочисленные отклики на предлагаемые Гречем изменения в составе русской азбуки, ведь в ней всё ещё оставались четыре буквы, ненужные для передачи русской речи: «і десятиричное», «фита», «ижица», «ять».

Все эти буквы были окончательно упразднены орфографической реформой 1917 - 1918 гг., которая упростила русское письмо и вызвала серьёзную критику со стороны И. А. Бунина, И. А. Ильина, В. И. Иванова и других выдающихся деятелей литературы и науки.

Рассмотрим второй тип исторических изменений алфавитно-буквенного состава русской азбуки. Некоторые буквы русской азбуки изменили своё значение и применение в связи с историческими изменениями в звуковом строе русского языка. Это прежде всего касается букв Ђ и ь.

Одним из основных фонетических процессов древнерусского языка, перестроившим его звуковую систему и приблизившим её к современному состоянию, был процесс падения, или утраты редуцированных. В древнерусском языке $\mathrm{b}$ (ep) обозначал краткий, ослабленный (редуцированный) звук, близкий к [о], а ь (ерь) - краткий, ослабленный (редуцированный) звук, близкий к [е], например: сънъ (сон), дьнь (день). Но к XIV веку эти буквы окончательно утратили своё звуковое значение в результате падения редуцированных и стали применяться для обозначения твёрдости - мягкости предшествующих согласных. Буква Ђ (ер) была сохранена только как разделительный знак, Ь (ерь) — как разделительный знак и для обозначения мягкости предшествующего согласного.

В конце слова употребление буквы Ђ (ер) было излишним, так как на твёрдость согласного указывало отсутствие буквы Ь (ерь). Однако вплоть до реформы 1917 - 1918 гг. букву Ђ (ер) в конце слова продолжали писать. Эта буква была «самой дорогой буквой мира» (Л.В. Успенский), так как 
употреблялась чаще других букв, а на конце слов ещё и без надобности, исключительно только по традиции.

В романе-эпопее Л.Н. Толстого «Война и мир» (издание 1897 года), по подсчётам Л.В. Успенского, буква Љ встречается 115 тысяч раз.

В результате утраты редуцированных (кратких) гласных звуков Ђ и Ь в русском языке появилось чередование гласных [о] и [э] с нулём звука (так называемые беглые гласные): лоб - лба, день - дня.

Более прочному усвоению данной темы, а также развитию орфографических навыков и ассоциативного мышления способствует проведение различного типа дидактических игр, например, «Третий лишний».

Найдите в каждом ряду «лишнее» слово и объясните свой выбор:

1) отец, мох, дом;

2) нос, весь, день;

3) лев, рожь, небо.

Утрата редуцированных (кратких) гласных Ђ и Б отразилась не только на письме, но и в произношении. Одним из следствий падения редуцированных гласных Ђ и Ь является оглушение звонких согласных в абсолютном конце слова. В словах, типа морозъ, плодъ, лобъ до падения редуцированных звонкий согласный перед гласным Ђ сохранял свою звонкость, после утраты конечного гласного Ђ звонкий согласный в абсолютном конце слова всегда оглушается (моро[c], пло[m], ло[n]).

В современном русском языке отношения между парными глухими и звонкими согласными фонемами заключаются в том, что они могут быть противопоставлены только в определенных фонетических положениях (перед гласными, сонорными согласными, а также перед [в]и [j]). В абсолютном конце слова и перед остальными согласными глухость-звонкость не различается. Чёткое представление о закономерностях развития таких фонетических особенностей русского языка, как оглушение и озвончение, 
поможет преподавателю правильно и логично подавать материал, составлять упражнения и задания.

Для активизации категории глухости-звонкости предназначена игра «Свой звук». Игра проводится командами. Преподаватель записывает на доске трудные для учащихся звуки (например, [б] - [п], [в] - [ф], [3] - [с] и т.д.) и показывает артикуляционные различия. Затем каждая команда получает карточки со «своими» звуками (по 2 или по 3). Преподаватель произносит слова, содержащие написанные на доске звуки, а члены команды (поочередно) показывают карточку, слыша слово с одним из «своих» звуков. За каждый правильный ответ игрок получает баллы. Данная игра может использоваться и как парная форма работы, в этом случае звуки распределяются между игроками в зависимости от индивидуальных трудностей студентов.

Игра «Веселая замена» способствует формированию навыка установления адекватных звуко-буквенных соответствий. Игрокам предлагаются слова, в которых замена первой буквы, обозначающей звонкий звук, на букву, обозначающую глухой звук, приводит к изменению значения слова. Например, Tом , тело , колос точка , корка -

почка слой , шалость Игру лучше проводить, когда соревнуются две команды. Игру «Веселая замена» можно проводить и с другим заданием: заменить последний звонкий согласный парным глухим согласным. Для игры можно предложить слова: плод, луг, род, молод, пруд, код.

Различным результатам падения редуцированных могут быть посвящены проблемные задания лингвистических игр и квестов, которые решаются «методом мозгового штурма».

Ещё один тип исторических изменений алфавитно-буквенного состава русской азбуки - введение недостающих новых букв. Несмотря на фонетическое богатство русской азбуки, в ней всё же отсутствовали буквы для 
передачи звуков [й] и [jo], ['o] - Ё, характерных для русской речи. С буквой Й (и краткое) всё понятно и просто: она была введена Академией наук при реформе 1735 года и с тех пор утвердилась в русской азбуке. Иначе обстоит дело с буквой Ё - одной из самых загадочных и многострадальных букв русской письменности. Более 200 лет назад она вошла в русский язык, но, к сожалению, до сих пор в русском письме не закрепилась.

Долгое время изобретение буквы Ё приписывали Н.М. Карамзину, и только в конце прошлого столетия стало известно имя истинного создателя этой буквы. Букву Ё предложила ввести в русскую азбуку Екатерина Романовна Дашкова. 18/ 29 ноября 1783 года президент Петербургской Академии наук обсуждала проект Словаря Академии Российской, по сути первого толкового словаря в нашей истории, и вдруг, улыбнувшись, предложила уважаемым академикам написать слово «ёлка». Увидев вариант «іолка», спросила, не лучше ли ввести новую букву Ё. Так родилась замечательная буква русской азбуки.

Значение буквы Ё для русской письменности прекрасно осознавали многие наши крупнейшие лингвисты, такие, например, как Лев Владимирович Щерба и Александр Александрович Реформатский. Л.В. Щерба отмечал, что «знаки Ё и Й надо обязательно считать за особые буквы», а введение обязательного употребления буквы Ё считал «делом первостепенной важности». А.А. Реформатский посвятил этой букве даже особую статью, призывая «юридически её узаконить в списке алфавита». Но до сих пор эту букву часто игнорируют, а ведь она имеет важное смыслоразличительное значение, например: все впереди или всё впереди. Многострадальной букве Ё в 2005 году был поставлен памятник в городе Ульяновске, где она красуется на двухметровой треугольной призме из красного гранита весом в три тонны.

После знакомства с историей русской азбуки можно предложить ряд игровых заданий. Например, студентам, поделённым на две команды, 
предлагается вспомнить и написать на карточках как можно больше пословиц и устойчивых выражений, в которых сохранились старые названия русских букв: от аза до ижицы - знать всё на свете, от начала до конца, от а до я; начинать с азов - с самого начала, с самого простого; сперва аз да буки, а там и науки - сперва выучи алфавит, а потом постигнешь и науки; ни аза в глаза ничего не знать; стоять фертом - стоять подбоченясь, «руки в боки», что похоже на букву Ф (ферт - название этой буквы в кириллице); сам ни аза в глаза, а людей ижицей тычет - человек ничего не знает (даже аза), а других упрекает в незнании чего-то более сложного (конечного); ставить покоем (столы) - поставить столы так, чтобы они образовали букву П; знать (сделать) на ять - очень хорошо, крепко; дойти до ижицы - сделать всё, что можно, дойти до конца; прописать ижицу - высечь, выпороть, наказать розгами или ремнём (по форме эта буква отчасти напоминает пучок розог или плётку) и др. Потом команды меняются карточками и объясняют значения пословиц и устойчивых выражений.

Ещё одно задание: придумайте такие высказывания, которые можно продолжить, и предложите сделать это другой команде. Например:

Заметно изменился количественный состав азбуки:

Изменилось звуковое значение некоторых букв:

Стало иным начертание некоторых букв:

Произошла смена названий следующих букв:

На протяжении почти тысячелетней истории русского письма в русской азбуке произошли такие изменения:

Обращение к истории языка также необходимо при изучении тем «Чередование гласных в корне», «Чередование согласных в корне», «Полногласные и неполногласные сочетания в современном русском языке».

История языка помогает объяснить некоторые явления в современном правописании, которые необъяснимы с точки зрения современного русского 
языка. Например, известно, что шипящие [ш'], [ж'] и аффрикаты [ч'], [ц'] в древнерусском языке были мягкими согласными. Эта их особенность и сейчас отражается в орфографии современного русского языка: мы пишем жизнь, шина, рожь, мышь, несешь, цирк, дочь, хотя произносим [ж], [ш] и [ц] твердо. Подобные написания называются историческими, или традиционными; иными словами, мы продолжаем писать так, как писали в эпоху мягкости шипящих и [ц']. Шипящие [ж'], [ш'] и аффрикаты [ч'] и [ц'] появились еще в праславянском языке в результате разного рода палатализаций (смягчения) определенных согласных звуков. Звук [ж'] восходит к [г], [3] и [д], звук [ш'] - к согласным [х] и $[c]$, звук [ч'] - к согласным [к], [т] и сочетаниям согласных [гт] и [кт], звук [ц'] - к согласному [к]. Шипящие [ж] и [ш] в древнерусском языке до XIV века были только мягкими, а после XIV века стали только твёрдыми. Аффриката [ц] отвердела только в XVI веке, а [ч'] сохраняет мягкость до сих пор. История этих согласных - это история их отвердения, причем данный процесс не является следствием падения редуцированных. С происхождением шипящих и аффрикат связаны и чередования согласных в корне, например: рука - ручка, дорога - дорожный, ухо - уши, лик - лицо, носить - ношу, любить - люблю, свет - свеча - освещение, водить - вожу - вождение.

Владение информацией по истории вышеназванных согласных поможет преподавателю в подготовке упражнений, закрепляющих орфографические навыки. Использование на занятиях игры «Какое слово звучит?» будет способствовать формированию навыка установления адекватных звукобуквенных соответствий. Обучаемые получают список из 10-20 слов. Их задача состоит в том, чтобы находить в списке слова, произнесенные преподавателем и ставить рядом с каждым из них соответствующий номер. Преподаватель читает слова со средней скоростью в произвольной последовательности. Например, книжка, цифра, муж, нож, чайник, живой, душ, шкаф, шаг, массаж, цирк, шуба, бумажка, жизнь, подушка, машина, 
чашка, шапка, бедняжка, лыжи. В качестве варианта этой игры можно дать задание: отметить только те слова, которые были произнесены. Для закрепления в памяти правильного произнесения изучаемого звука можно предложить игру «Кто больше?» Преподаватель предлагает обучаемым звук, а они должны назвать как можно больше слов, начинающихся с этого звука. Например, [ж] - жизнь, жара, жадность, жалко, живой, жёлтый жена, животное, жидкий. Тот, кто назвал последнее слово, выигрывает. Эту игру можно дополнить орфографическим заданием. И тогда победитель тот, кто больше и быстрее всех написал, а потом и произнес записанные слова.

Для формирования фонематического слуха и навыков дифференциации звуков можно предложить игру «Слышу - не слышу». В игре участвуют две команды. Ведущий (преподаватель) произносит слова со звуками, которые вызывают сложности у учащихся, например, со звуками [ж] - [ш], [с] -[ц] и др. А учащиеся, слыша один звук, поднимают правую руку, а слыша другой левую. Судья (один из студентов или преподаватель) фиксирует ошибки на доске. Побеждает та команда, которая допустила меньше ошибок.

В современной научной этимологии решающим является фонетический, а не семантический критерий; в методике преподавания - семантический. Это означает, что при анализе примеров в игровой форме обучаемый должен в первую очередь увидеть общий признак, лежащий в основе анализируемых слов.

Так, например, рассматривая этимологическое родство представленных слов: а) соха - сохатый - посох; б) пригожий - негодяй; в) стол- постель; г) еда - яд-яство, студент должен рассуждать следующим образом: соха coxambiŭ - nocox - этимологически родственны, так как слово соха исторически значит 'кол, дерево с развилком'; благодаря метафорическому переносу олень назван сохатым, так как имеет ветвистые рога; в слове посох корень сох- употреблен в прямом значении 'кол', а приставка по- имеет 
значение 'похожий на то, что названо корнем' (ср. в другом фонетическом облике паводок, пасынок, патрубок).

Стол- постель: этимологически родственные, так как их общая идея связи с глаголом стелить. Корни стол- и стел- связаны историческим чередованием е//o, которое обнаруживается в целом ряде слов русского языка: нести - ноша, везти - воз, плести - плот, велеть - воля и др. Нетрудно заметить, что гласный $е$ употребляется в глаголах, обозначающих действие, а гласный $o-$ в существительных, обозначающих результат этого действия. Таким образом, стол - это результат действия (стелить, стлать).

Полезны также сопоставления русских слов и иноязычных заимствований, восходящих к тому же индоевропейскому корню, например, nana - патрищий - патриот - патрон; портик-портал-паспорт - парить - переть и другие.

Сведения о полногласных и неполногласных сочетаниях помогут повысить орфографическую грамотность иностранных учащихся и будут способствовать более точному и тонкому пониманию текстов, особенно произведений русской классической литературы. Полногласные и неполногласные сочетания в корне слова - результат изменения дифтонгических сочетаний *or, *ol, *er, *el в положении между согласными, которые по-разному проявились в разных группах славянских языков. У восточных славян после согласного появляется гласный, подобный гласному перед плавным сонорным (полногласие), а у южных славян в данных дифтонгических сочетаниях происходит метатеза (гласный и согласный меняются местами) и удлинение гласного (неполногласие). Таким образом, в современном русском языке слова с полногласными сочетаниями оро, оло (ело), ере - исконно русские по происхождению (сторона, город, холод, голова, молоко, дерево, берег), а слова с неполногласными сочетаниями $p a$, ла, $p e$, ле заимствованы из старославянского языка (страна, град, хлад (прохладный), глава, млеко (Млечный путь), древо, брег (прибрежный)). 
На закрепление данной темы можно предложить игру «Найди пару». Задание: выпишите однокоренные слова парами и выделите чередующиеся сочетания звуков, например, ворота - вратарь.

Огород, страна, платье, согласный (звук), полотно, молоко, голос, младенец, сторона, ограда, молодежь, млекопитающее.

В современном русском языке встречаются однокоренные слова с начальными сочетаниями ро, ло и ра, ла перед согласным. Это результат исторического изменения дифтонгических сочетаний *ol, *or в начале слова (корня) перед согласным, которое также проходило по-разному у восточных и южных славян. Слова с начальными сочетаниями ро, ло - исконно русские (восточнославянские): подросток, рост, ровный, роспись, розыгрыш, лодка, локоть, а слова с начальными сочетаниями $p a$, ла заимствованы из старославянского языка: возраст, равенство, расписка, разыграть, ладья.

Оживить занятие и способствовать более глубокому усвоению данной темы поможет игра «Весёлый мяч». Преподаватель называет слово с начальным сочетанием (корня или приставки) ра, ла и бросает мяч учащемуся, который должен его поймать и назвать однокоренное слово с начальным ро, ло (корня или приставки). Например, возраст - рост, расчертить - росчерк, ладья лодка, расписка - роспись, разыграть - розыгрыш, равный - ровный. Можно усложнить эту игру заданием: не только назвать однокоренное слово, но и объяснить его значение.

\section{Заключение}

Предложенный материал позволит, активно развивая лингвистические и общекультурные компетенции, совершенствовать знания иностранных студентов в области русского языка и его истории. Практика использования игровых технологий при обучении русскому языку как иностранному убеждает в том, что лингвистическая игра имеет большой потенциал и претендует на значимое место в системе языковых занятий. 


\section{Литература}

1- Васильев Н.Л., Попович Т. (2015) Интегративный потенцุиал вузовского курса «История русского литературного языка» // Интеграџия образования, T. 19. № 3 (80). C. 85-90.

2- Крючкова Л.С., Мощинская Н.В. (2009) Практическая методика обучения русскому языку как иностранному. Учебное пособие для начинающего преподавателя, для студентов-филологов и лингвистов, специализирующихся по РКИ. Москва: Изд-во «Флинта:Наука».

3- Лейчик В.М., Никулина Е.А. (2012) Модернизачия обучения русскому языку в иноязычной аудитории // Русский язык за рубежом, № 3. С. 28-33.

4- Матохина А.В., Харламова Н.В., Шабалина О.А., Куликов Е.А. (2017) Использование игровых образовательных технологий в системе обучения русского как иностранного языка в современном вузе // Открытое образование, Т. 21. № 3. С. 39-47.

5- Эльконин Д.Б. (1987) Психология игры. Москва: Изд-во «Просвещение».

\section{Bibliography}

1- Vasil'ev N.L., Popovich T. (2015) Integrativnyj potencial vuzovskogo kursa «Istorija russkogo literaturnogo jazyka»// Integracija obrazovanija, T. 19. № 3 (80). S. 85-90.

2- Krjuchkova L.S., Moshhinskaja N.V. (2009) Prakticheskaja metodika obuchenija russkomu jazyku kak inostrannomu. Uchebnoe posobie dlja nachinajushhego prepodavatelja, dlja studentov-filologov i lingvistov, specializirujushhihsja po RKI. Moskva: Izd-vo «Flinta:Nauka».

3- Lejchik V.M., Nikulina E.A. (2012) Modernizacija obuchenija russkomu jazyku v inojazychnoj auditorii // Russkij jazyk za rubezhom, № 3. S. 28-33.

4- Matohina A.V., Harlamova N.V., Shabalina O.A., Kulikov E.A. (2017) Ispol'zovanie igrovyh obrazovatel'nyh tehnologij v sisteme obuchenija russkogo kak inostrannogo jazyka v sovremennom vuze // Otkrytoe obrazovanie, T. 21. № 3. S. $39-47$.

5- Jel'konin D.B. (1987) Psihologija igry. Moskva: Izd-vo «Prosveshhenie».

\section{HOW TO CITE THIS ARTICLE}

Сарапас M. B. (2020). Playing Technologies as Mean for Development of Linguistic Competence of Foreign Students during Studying of Language History. Issledovatel'skiy Zhurnal Russkogo Yazyka I Literatury, 8(1), 103-119.

DOI: 10.29252 /iarll.15.103

URL: http://www.journaliarll.ir/index.php/iarll/article/view/111 
فناورىهاى بازى به عنوان ابزار ايجاد مهارتهاى زبانى دانشجويان خارجى

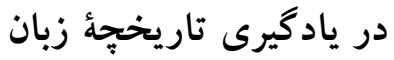

\author{
مارينا ولاديميروونا ساراياس' \\ دانشيار، دانشكاه دولتى علوم تربيتى و بِداكوزيك مسكو، ولني

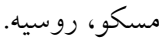 \\ (تاريخ دريافت: زوئيه 19 +r؛ تاريخ بذيرش: دسامبر 19.r)
}

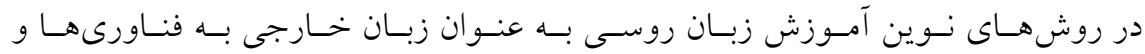

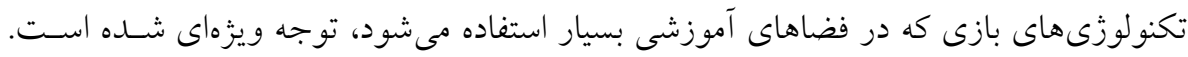

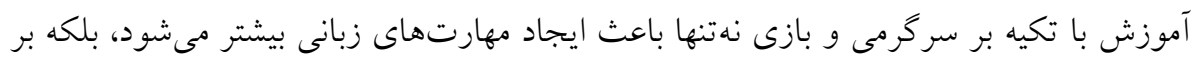

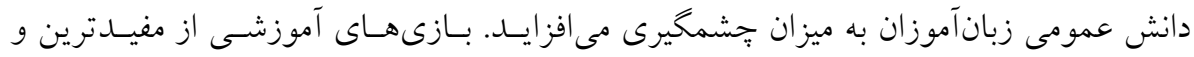

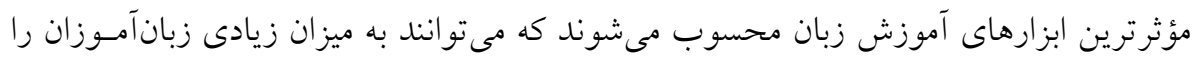

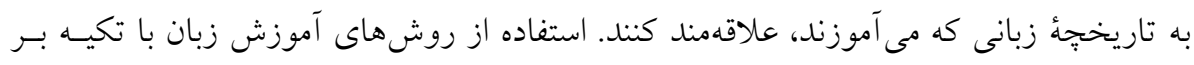

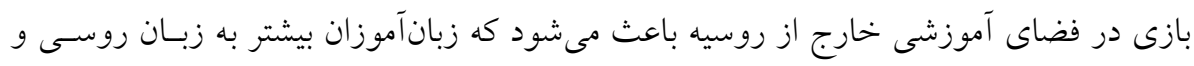

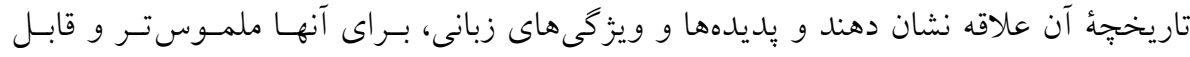

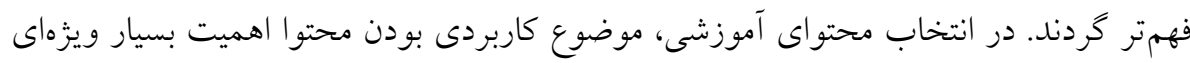

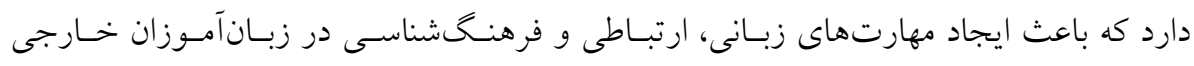

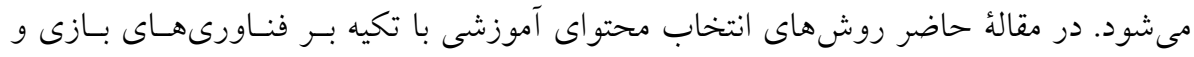

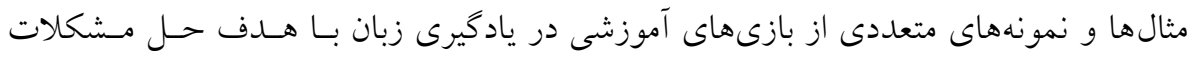

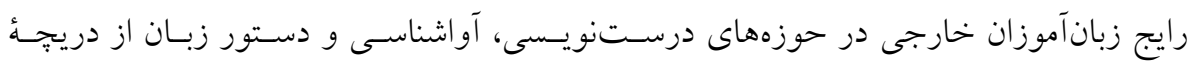
تاريخجه زبان روسى ارائه مى زردند.

وازگًان كليدى: زبان روسى به عنوان زبان خارجى، روشهاى آموزش زبان روسى به عنوان زبـان

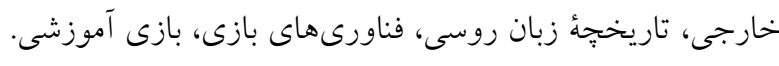

